OPEN ACCESS

Edited by:

Luigi Lucini,

Catholic University of the Sacred

Heart, Italy

Reviewed by:

Antonella Castagna,

University of Pisa, Italy

Petronia Carillo,

University of Campania Luigi

Vanvitelli, Italy

Mariela I. Monteoliva,

Instituto Nacional de Tecnología

Agropecuaria, Argentina

*Correspondence:

Xiangru Tang

tangxr@scau.edu.cn

orcid.org/0000-0001-7943-4474

tThese authors have contributed equally to this work

Specialty section:

This article was submitted to Crop and Product Physiology,

a section of the journal

Frontiers in Plant Science

Received: 28 September 2021 Accepted: 08 November 2021 Published: 26 November 2021

Citation: Luo H, Duan M, Kong L, He L, Chen Y, Wang Z and Tang X (2021)

The Regulatory Mechanism of 2-Acetyl-1-Pyrroline Biosynthesis in Fragrant Rice (Oryza sativa L.) Under Different Soil Moisture Contents.

Front. Plant Sci. 12:772728.

doi: 10.3389/fp/s.2021.772728

\section{The Regulatory Mechanism of} 2-Acetyl-1-Pyrroline Biosynthesis in Fragrant Rice (Oryza sativa L.) Under Different Soil Moisture Contents

\author{
Haowen Luo ${ }^{1,2,3 \dagger}$, Meiyang Duan ${ }^{1,2,3 \dagger}$, Leilei Kong ${ }^{4}$, Longxin He ${ }^{1,2,3}$, Yulin Chen ${ }^{5}$, \\ Zhimin Wang ${ }^{6}$ and Xiangru Tang ${ }^{1,2,3 *}$ \\ 'State Key Laboratory for Conservation and Utilization of Subtropical Agricultural Bioresources, South China Agricultural \\ University, Guangzhou, China, ${ }^{2}$ Scientific Observing and Experimental Station of Crop Cultivation in South China, Ministry of \\ Agriculture, Guangzhou, China, ${ }^{3}$ Guangzhou Key Laboratory for Science and Technology of Aromatic Rice, Guangzhou, \\ China, ${ }^{4}$ Rice Research Institute, Guangdong Academy of Agricultural Sciences/Guangdong Key Laboratory of New \\ Technology in Rice Breeding/Guangdong Rice Engineering Laboratory, Guangzhou, China, ${ }^{5}$ College of Natural Resources \\ and Environment, College of Agriculture, South China Agricultural University, Guangzhou, China, ${ }^{6}$ College of Engineering, \\ South China Agricultural University, Guangzhou, China
}

2-acetyl-1-pyrroline (2-AP) is the key compound of rice aroma. However, the responses of 2-AP biosynthesis in fragrant rice under different soil moisture and the corresponding mechanism are little known. The present study evaluated the effects of different soil moisture on 2-AP biosynthesis through a pot experiment. Four soil moisture contents, that is, 50\% (SM50), 40\% (SM40), 30\% (SM30), and 20\% (SM20), were adopted, and SM50 treatment was taken as control. The pots were weighed and watered to maintain the corresponding soil moisture content. The results showed no significant difference in growth parameters (plant height, stem diameter, and plant dry weight) among all treatments. Compared with SM50, SM40, SM30, and SM20 treatments significantly $(p<0.05)$ increased 2-AP content by 32.81, 23.18, and 53.12\%, respectively. Between 20 to $90 \%$ higher proline content was observed in SM40, SM30, and SM20 treatments than in SM50. Enzymes including proline dehydrogenase, ornithine transaminase, and 1-pyrroline-5carboxylate synthetase exhibited lower activities with soil moisture declined. Higher diamine oxidase activity was observed in SM40, SM30, and SM20 treatments compared with SM50, and real-time PCR analyses showed that transcript level of DAO1 was greatly increased under low soil moisture treatments, especially in SM20 treatment. Transcript levels of PRODH, DAO2, DAO4, DAO5, OAT, P5CS1, and P5CS2 decreased or maintained in SM40, SM30, and SM20 treatments compared with SM50. We deduced that low soil moisture content enhanced 2-AP biosynthesis mainly by upregulating the expression of DAO1 to promote the conversion from putrescine to 2-AP.

Keywords: fragrant rice, 2-acetyl-1-pyrroline, gene expression, enzymes, proline, soil moisture 


\section{INTRODUCTION}

Fragrant rice is famous for its special aroma in the world (Dumitrascu et al., 2021; Moogi et al., 2021), and 2-acetyl-1pyrroline (2-AP) has been identified as the key and main component of that aroma in recent years (Jezussek et al., 2002; Mahattanatawee and Rouseff, 2014; Poonlaphdecha et al., 2016). Over the past two decades, scientists have made attempts to understand the biosynthetic mechanism of 2-AP. The studies by Yoshihashi et al. (2002) and Poonlaphdecha et al. (2016) revealed that proline, glutamic acid, ornithine, and 1-pyrroline are the important precursors of 2-AP. Kaikavoosi et al. (2015) found that pyrroline-5-carboxylate synthetase (P5CS) and the genes encoding it are involved in 2-AP biosynthesis. The study by Chen et al. (2008) found that the expression of gene BADH2 is important for regulating 2 -AP content in fragrant rice because it inhibits 2-AP production by encoding betaine aldehyde dehydrogenase $(\mathrm{BADH})$, which prevents the conversion from $\gamma$-aminobutyric aldehyde to 1 -pyrroline by turning $\gamma$-aminobutyric aldehyde into $\gamma$-aminobutyric acid (GABA). The potential 2-AP biosynthesis in fragrant rice is presented in Figure $\mathbf{1}$.

The irrigation regime could substantially influence the 2-AP content. Mo et al. (2019a) indicated that moderate drought management (soil water potential was between -15 and $-25 \mathrm{kPa}$ ) at the booting stage could remarkably increase grain 2-AP content. Deng et al. (2018) demonstrated that mild drought treatment (the soil water potential was $-25 \mathrm{kPa}$ ) during the grain-filling stage also increased grain 2-AP. An earlier study also showed that different water regimes at tillering stage induced regulations in levels of 2-AP and its precursors (Li et al., 2021). Those studies found that drought treatment could cause 2-AP increment, accompanied by upregulation of proline content, and thus, they deduced that drought increased 2-AP by increasing proline content and thus promoting the conversion from proline to 2-AP. However, this theory lacks data support at the molecular level, and more studies should be conducted at the physiological level. In 2018, the study by Bao et al. (2018) showed that alternate wetting and drying irrigation during the grain-filling stage greatly increased grain 2-AP content by upregulating the proline content, and the activity of proline dehydrogenase $(\mathrm{PDH})$ and expression of $\mathrm{PRODH}$ were also upregulated. Therefore, they believed that increased 2-AP was converted from accumulated proline under the irrigation strategy. However, alternate wetting and drying irrigation includes dehydration and recovery parts, while recovery would induce proline degradation as reported by a previous study (Foster et al., 2015). Those studies cannot elaborate on the mechanism of 2-AP biosynthesis under different soil water conditions.

Water management would change and control the soil moisture, while many physiological activities of crops are sensitive to the change of soil moisture. The research of Thai et al. (2019) revealed that as soil moisture declined, photosynthetic parameters of sugarcane decreased to some degree, and a soil moisture level of $10 \%$ might be the critical point beyond which irrigation results in photosynthetic disorders. Zhang et al. (2021) demonstrated that the degree of soil drying substantially influenced the yield formation of rice. Farrell et al. (2017) indicated that plant species vary relative water content (RWC) and water potential at turgor loss point and concomitant drought sensitivity. The studies on soil moisture-induced physiological and biochemical responses are important to understand the

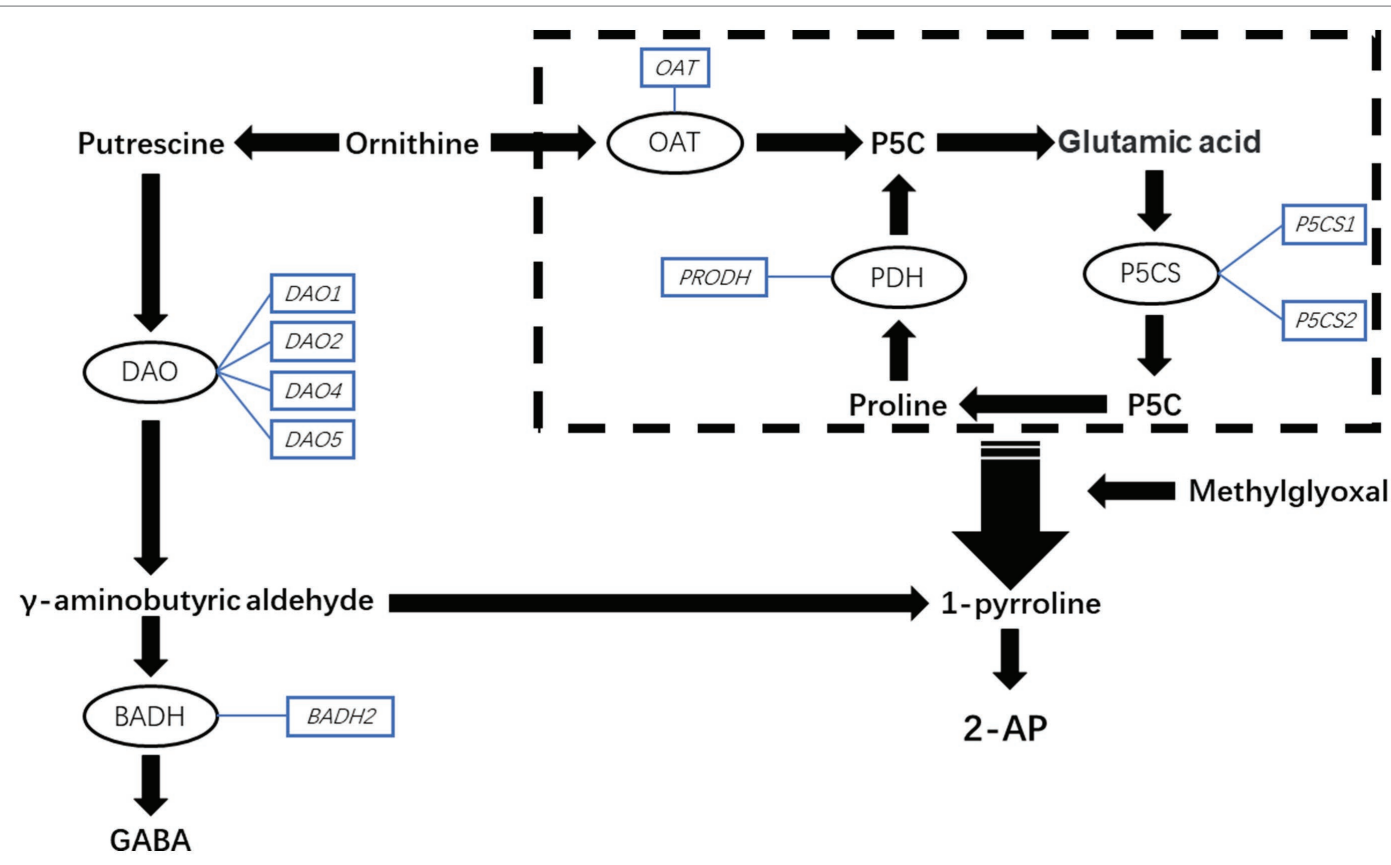

FIGURE 1 | The schematic representation of the potential pathway of 2-AP biosynthesis in fragrant rice. GABA, $\gamma$-aminobutyric acid; P5CS, 1-pyrroline-5carboxylate synthetase; PDH, proline dehydrogenase; OAT, ornithine transaminase; BADH, betaine aldehyde dehydrogenase; DAO, diamine oxidase; P5C, pyrroline5-carboxylic acid. 
regulatory mechanism of water management on 2-AP biosynthesis and propose practical irrigation strategies to achieve the goal of high yield and high aroma in fragrant rice production. Little is known; however, the response of 2-AP level to different soil moisture and the related mechanism at the physiological and molecular levels has rarely been reported.

The objectives of this study were to evaluate the effects of different soil moisture content on 2-AP biosynthesis and the mechanism behind it. Besides 2-AP, eight compounds, nine genes, and five enzyme activities involved in 2-AP biosynthesis were determined under different soil moisture treatments. Such a study would provide new and further information about the physiological mechanism of 2-AP biosynthesis in fragrant rice.

\section{MATERIALS AND METHODS}

\section{Plant Materials, Growth Condition, and Experimental Design}

The pot experiment was conducted in an artificial climate chamber in the College of Agriculture, South China Agricultural University, Guangzhou, China. The parameters of the chambers were set as $28 / 25^{\circ} \mathrm{C}$ day/night temperature and $70 \%$ air relative humidity. The seeds of a fragrant rice cultivar, Xiangyaxiangzhan, which was widely planted in South China, were used as plant materials in the experiment. After germination, rice seeds were sowed in hydroponic boxes, and then, the rice seedlings were allowed to grow in a commercial hydroponic solution (Hyponex, Osaka, Japan) under controlled conditions (temperature: $26 \pm 2^{\circ} \mathrm{C}$ ) according to the methods of Mostofa et al. (2020). Then, 16-dayold healthy seedlings were transplanted into pretreated and soilcontained pots with nine seedlings per pot. Each pot was filled with $500 \mathrm{~g}$ dry soil before, and 10 pots were used for each treatment. Before transplanting, each pot was watered to reach the corresponding soil moisture, and four soil moisture contents were set as 20\% (SM20), 30\% (SM30), 40\% (SM40), and 50\% (SM), respectively. The soil moisture percentage means the proportion of water weight to dry soil weight. The pots were weighed and watered every $8 \mathrm{~h}$ to maintain the corresponding soil moisture. The experimental soil was sandy loam containing $11.85 \mathrm{~g} \mathrm{~kg}^{-1}$ organic matter, $0.46 \mathrm{~g} \mathrm{~kg}^{-1}$ total nitrogen, $0.31 \mathrm{~g} \mathrm{~kg}^{-1}$ total phosphorus, $17.59 \mathrm{~g} \mathrm{~kg}^{-1}$ total potassium, $10.05 \mathrm{mg} \mathrm{kg}^{-1}$ available phosphate, $27.83 \mathrm{mg} \mathrm{kg}^{-1}$ available nitrogen, $52.43 \mathrm{mg} \mathrm{kg}^{-1}$ available potassium, and $6.08 \mathrm{pH}$. The saturated soil moisture was $53.68 \%$ (proportion of water weight to dry soil weight).

\section{Measurements of Plant Growth Parameters and Sampling}

Ten days after receiving soil moisture treatments, nine seedlings were randomly selected and taken from each treatment to immediately measure the fresh weight, plant height, and stem width. Then, the seedlings were subjected to oven-drying at $80^{\circ} \mathrm{C}$ for $48 \mathrm{~h}$ to determine the dry weight, and RWC was calculated using the methods of Mostofa et al. (2020). To determine metabolite contents and enzyme activities, three pots were selected as three biological replicates in each treatment.
The fresh leaves were sampled and stored at $-80^{\circ} \mathrm{C}$, and the determination was repeated thrice for the individual parameters. For gene expression analysis, another three pots were selected as three biological replicates in each treatment, and about $1.00 \mathrm{~g}$ of fresh leaves of each pot was separately sampled and stored at $-80^{\circ} \mathrm{C}$ for quantitative real-time polymerase chain reaction (qRT-PCR).

Determination of 2-AP, 1-pyrroline, proline, methylglyoxal, glutamic acid, soluble protein, soluble sugar, GABA, and $\mathrm{P} 5 \mathrm{C}$ contents.

The 2-AP content was determined with synchronization distillation and extraction method (SDE) combined with GCMS-QP 2010 Plus (Shimadzu Corporation, Japan) according to the methods of Bao et al. (2018). The final 2-AP content was expressed as $\mu \mathrm{g} \mathrm{kg}^{-1}$ fresh weight (FW).

The determination of 1-pyrroline content was carried out with the methods of Hill (1967). The reaction system contained $1 \mathrm{ml}$ of $0.01 \mathrm{M}$ 2-amino benzaldehyde (in $0.02 \mathrm{M}$ phosphate buffer, $\mathrm{pH} 7.0$ ), $1 \mathrm{ml}$ of $0.2 \mathrm{M}$ phosphate buffer, and $1 \mathrm{ml}$ of distilled water. The 1-pyrroline concentration was calculated with the molar extinction coefficient $\left(\varepsilon=1860 \mathrm{~cm}^{-1}\right)$ after the absorbance was read at $430 \mathrm{~nm}$. The final 1-pyrroline content was expressed as $\mu \mathrm{molg}^{-1} \mathrm{FW}$.

The determination of glutamic acid content was carried out according to Wang et al. (2005). After reacting with $0.5 \%$ 2,2-dihydroxyindane-1,3-dione at boiling water bath for $20 \mathrm{~min}$, the absorbance was read at $569 \mathrm{~nm}$, and the concentration was calculated from a standard curve (the glutamic acid standard curve was made using L-glutamic acid (CAS: 56-86-0) as standard compound). The final glutamic acid content was expressed as $\mathrm{mgg}^{-1} \mathrm{FW}$.

The determination of proline content was carried out with the method of Bates et al. (1973). The sample (about 0.1 g) was homogenized in $2 \mathrm{ml}$ of $3 \%$ sulfosalicylic acid and boiled for $10 \mathrm{~min}$ in water bath. The $0.5 \mathrm{ml}$ of the filtrate was mixed with ninhydrin reagent $(0.5 \mathrm{ml})$ and glacial acetic acid $(0.5 \mathrm{ml})$. The reaction mixture was again placed in boiling water bath for $30 \mathrm{~min}$ and then extracted with $1.5 \mathrm{ml}$ of toluene. The absorbance was measured at $520 \mathrm{~nm}$, and the concentration was calculated from a standard curve. The final proline content was expressed as $\mu \mathrm{gg}^{-1} \mathrm{FW}$.

The determination of methylglyoxal content was carried out with the methods of Banu et al. (2010). In a total volume of $1 \mathrm{ml}, 250 \mu \mathrm{l}$ of 1,2 -diaminobenzene, $100 \mu \mathrm{l}$ of perchloric acid, and $650 \mu \mathrm{l}$ of the neutralized supernatant were added in that order. Then, the absorbance of the derivative was read at $336 \mathrm{~nm}$, and the concentration was calculated from a standard curve. The final methylglyoxal content was expressed as $\mathrm{mgg}^{-1}$ FW.

The determination of soluble protein content was carried out according to Mostofa et al. (2020). $0.2 \mathrm{ml}$ of extracting solution reacted with $1.0 \mathrm{ml}$ of Coomassie Brilliant Blue G250 Reagent at room temperature for $20 \mathrm{~min}$. The absorbance of the derivative was read at $595 \mathrm{~nm}$, and the concentration was calculated from a standard curve [the protein a standard curve was made using bovine serum albumin (CAS: 9048-46-8) as standard compound]. The final soluble protein content was expressed as $\mathrm{mgg}^{-1} \mathrm{FW}$. 
The determination of soluble sugar content was carried out according to Mostofa et al. (2020). About $0.1 \mathrm{~g}$ sample was extracted using $10 \mathrm{ml}$ of distilled water and boiled for $20 \mathrm{~min}$. The $0.2 \mathrm{ml}$ of the filtrate was mixed with $1.0 \mathrm{ml}$ anthrone. The reaction mixture was again placed in a boiling water bath for $20 \mathrm{~min}$. The absorbance was measured at $620 \mathrm{~nm}$. The concentration was calculated from a standard curve (the sugar standard curves were made using D-glucose anhydrous (CAS: 50-99-7) as standard compound). The final soluble sugar content was expressed as $\mu \mathrm{gg}^{-1} \mathrm{FW}$.

The determination of GABA content was carried out with the methods of Bao et al. (2018). The extraction solution contained $60 \%$ ethanol, $60 \mathrm{mM}$ lanthanum chloride, and $1 \mathrm{M}$ $\mathrm{KOH}$. The supernatant was added to $0.2 \mathrm{M}$ borate buffer $(\mathrm{pH}$ 10.0 ) and $6 \%$ phenol solution, and sodium hypochlorite (available chlorine, 10\%) was added while shaking. The absorbance was measured at $645 \mathrm{~nm}$, and the concentration was calculated from a standard curve. The final GABA content was expressed as $\mu \mathrm{gg}^{-1}$ FW.

The determination of $\mathrm{P} 5 \mathrm{C}$ content was carried out with the methods of Bao et al. (2018). The extraction solution contained $50 \mathrm{mM}$ Tris- $\mathrm{HCl}(\mathrm{pH} 8.0), 10 \%$ glycerol, $1 \%$ triton100 , and $1 \% \beta$-mercaptoethanol. The supernatant was added to a mixture containing $10 \%$ trichloroacetic acid (TCA) and $40 \mathrm{mM} \gamma$-aminobenzaldehyde. The P5C concentration was calculated with the molar extinction coefficient $\left(\varepsilon=2.58 \mathrm{mM} \mathrm{cm}^{-1}\right)$ after the absorbance was read at $430 \mathrm{~nm}$. The final P5C content was expressed as $\mu \mathrm{molg}^{-1} \mathrm{FW}$.

\section{Assay of Enzymes (P5CS, PDH, Ornithine Transaminase, Betaine Aldehyde Dehydrogenase, and Diamine Oxidase) Activities}

P5CS activity was determined according to the methods of Sánchez et al. (2002). The $0.5 \mathrm{ml}$ of reaction mixture volume contained $50 \mathrm{mmol} / \mathrm{L}$ Tri- $\mathrm{HCl} \mathrm{pH} \mathrm{7.0,50} \mathrm{mmol/L} \mathrm{L-glutamate,}$
$20 \mathrm{mmol} / \mathrm{L} \quad \mathrm{MgCl}_{2}, \quad 10 \mathrm{mmol} / \mathrm{L} \quad \mathrm{ATP}$, and $100 \mathrm{mmol} / \mathrm{L}$ hydroxamate- $\mathrm{HCl}$. The absorbance was read at $535 \mathrm{~nm}$ after the reaction. The determination of $\mathrm{PDH}$ activity was carried out according to Ncube et al. (2013) methods, and the absorbance was read at $440 \mathrm{~nm}$ after the reaction. The determination of OAT activity was carried out according to the methods of Deng et al. (2018). The reaction mixture contained $100 \mathrm{mM}$ potassium phosphate buffer ( $\mathrm{pH} 8.0$ ), $1 \mathrm{mM}$ pyridoxal-5phosphate, $50 \mathrm{mM}$ ornithine, $20 \mathrm{mM} \alpha$-ketoglutarate, and the enzyme extract $(0.1 \mathrm{ml})$. After incubation of the assay mixture for $30 \mathrm{~min}$, the absorbance was read at $440 \mathrm{~nm}$. The determination of $\mathrm{BADH}$ activity was carried out according to Yan et al. (2012), and the activity was both expressed as $\mathrm{Ug}^{-1} \mathrm{~h}^{-1}$. DAO activity was determined according to the methods of Yang et al. (2011). Reaction solutions $(2.9 \mathrm{ml})$ contained $2.0 \mathrm{ml}$ of $70 \mathrm{mmol} / \mathrm{l}$ sodium phosphate buffer, $0.5 \mathrm{ml}$ of crude enzyme extracts, $0.1 \mathrm{ml}$ of horseradish peroxidase, and $0.2 \mathrm{ml}$ of 4-aminoantipyrine/N,N-dimethylaniline. The reaction was initiated by adding $0.1 \mathrm{ml}$ of putrescine, and the absorbance was read at $555 \mathrm{~nm}$.

\section{Real-Time Quantitative RT-PCR}

Total RNA was extracted using the HiPure Plant RNA Mini Kit (Magen, Guangzhou, China). The quality and quantity of RNA were assessed by NanoDrop 2000. The Hiscript II QRT SuperMix for qPCR (+gDNAwiper; Vazyme, Nanjing, China) synthesized cDNA from total RNA. Real-time quantitative RT-PCR (qRT-PCR) was conducted in the CFX96 real-time PCR System (Bio-Rad, Hercules, CA, United States). Actin was used as an internal reference gene. Primers used for qRT-PCR are listed in Table 1. All primers were designed using the software tool Primer 5.

\section{Data Analysis}

All the obtained data were subjected to a one-way analysis of variance (ANOVA) using Statistix 8.1 (Analytical Software,

TABLE 1 | Primer sequences of genes encoding enzymes involved in 2-AP biosynthesis.

\begin{tabular}{|c|c|c|}
\hline Gene name & Accession no. & Primer sequences \\
\hline Proline dehydrogenase $(P R O D H)$ & AP014966.1 & $\begin{array}{l}\text { F 5'-TCATCAGACGAGCAGAGGAGAACAGG-3' } \\
\text { R 5'-CCCAGCATTGCAGCCTTGAACC-3' }\end{array}$ \\
\hline Pyrroline-5-carboxylic acid synthetase1 (P5CS1) & AP014961.1 & $\begin{array}{l}\text { F 5'-TाTGAGTCCCGACCTG-3' } \\
\text { R 5'-TTCACCAACATTACGAGGA-3' }\end{array}$ \\
\hline Pyrroline-5-carboxylic acid synthetase2 (P5CS2) & AP014957.1 & $\begin{array}{l}\text { F 5'-GAGGTTGGCATAAGCACAG-3' } \\
\text { R 5'-CTCCCTTGTCGCCGTTC-3' }\end{array}$ \\
\hline Ornithine aminotransferase (OAT) & AP014959.1 & $\begin{array}{l}\text { F 5'-GCCCTTGGTGCTGGAGTA-3' } \\
\text { R 5'-AGCCCTTTCAACGAGACCTT-3' }\end{array}$ \\
\hline Diamine oxidase1 (DAO1) & AP014962.1 & $\begin{array}{l}\text { F 5'-ATGGCACCCGGAACTCTTC-3' } \\
\text { R 5'-GCCTCAGTCTCGGCAACCTC-3' }\end{array}$ \\
\hline Diamine oxidase2 (DAO2) & AP014960.1 & $\begin{array}{l}\text { F 5'-TCGTTCGCATCAAGGTTGG-3' } \\
\text { R 5'-TCAGACAGAAGGGTGCCGTA-3' }\end{array}$ \\
\hline Diamine oxidase4 (DAO4) & AP014960.1 & $\begin{array}{l}\text { F 5'-TGGCAAGATAGAAGCAGAAGT-3' } \\
\text { R 5'-GTCCATACGGGCAACAAA-3' }\end{array}$ \\
\hline Diamine oxidase5(DAO5) & AP014958.1 & $\begin{array}{l}\text { F 5'-TGGCAAGATAGAAGCAGAA-3' } \\
\text { R 5'-TCCATACGGGCAACAAA-3' }\end{array}$ \\
\hline Betaine aldehyde dehydrogenase (BADH2) & AB09683 & $\begin{array}{l}\text { F 5'-GGTTGGTCTTCCTTCAGGTGTGC-3' } \\
\text { R 5'-CATCAACATCATCAAACACCACTAT-3' }\end{array}$ \\
\hline
\end{tabular}


Tallahassee, FL, United States). Statistix 8.1 was also used to perform correlation analysis, and the heatmap for the investigated parameters was established with Microsoft Excel. The differences among means were separated using the least significant (LSD) test at the 5\% probability level. Sigma Plot 9.0 (Systat Software Inc., San Jose, CA, United States) was used to make figures.

\section{RESULTS}

\section{2-AP Content}

The 2-AP content under different soil moisture is shown in Figure 2. The lowest 2-AP content was recorded in the control (SM50 treatment), while the highest 2-AP content was recorded in SM20 treatment. Compared with SM50, SM40, SM30, and SM20 treatments significantly $(p<0.05)$ increased 2 -AP content by $32.81,23.18$, and $53.12 \%$, respectively. There was no significant difference between SM40 and SM30 treatments.

\section{Growth Parameters}

The plant height, stem width, fresh weight, dry weight, and relative water content of fragrant rice under different soil moisture are shown in Table 2. There was no significant $(p<0.05)$ difference among the four treatments in plant height, stem width, and dry weight. Compared with SM50, SM40, SM30, and SM20 treatments significantly decreased the fresh weight of fragrant rice by $8.82,10.29$, and $9.17 \%$, respectively.

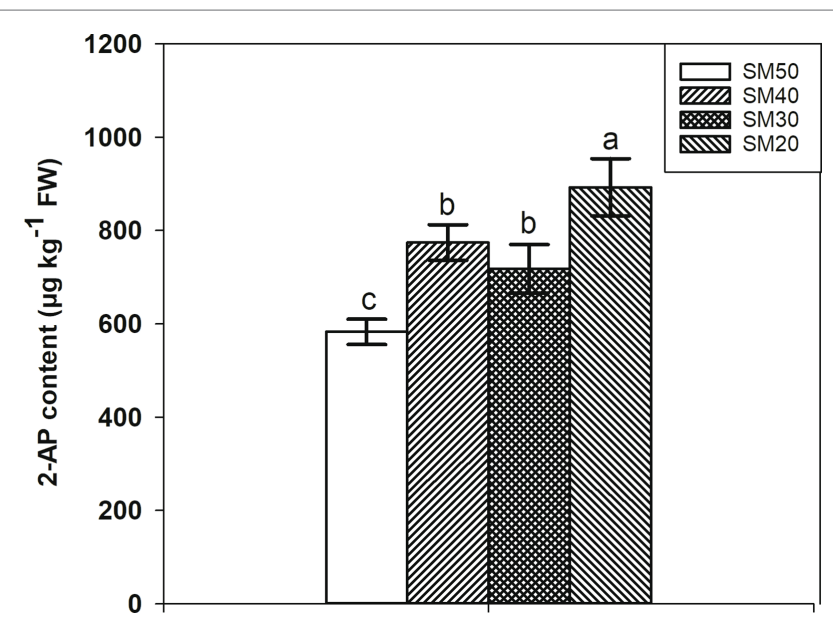

FIGURE 2 | Increase of 2AP content in fragrant rice with reduction of soil moisture. Each column represents the mean of three data \pm standard error $(n=3)$. Bars sharing a common letter do not differ significantly at $p<0.05$.
The differences in fresh weight among SM40, SM30, and SM20 treatments were not significant. The relative water content was between 75 and $77 \%$, with a slight reduction with the decline of the soil moisture.

\section{1-Pyrroline, Methylglyoxal, Glutamic Acid, Proline, GABA, P5C Contents, Soluble Protein, and Soluble Sugar Contents}

Different soil moisture substantially affected the contents of many biochemical substances (Figure 3). Compared with SM50 treatment, SM40, SM30, and SM20 treatments significantly $(p<0.05)$ increased 1-pyrroline content by $4.22,7.83$, and $12.46 \%$. Higher methylglyoxal contents were recorded in SM40, SM30, and SM20 treatments compared with SM50. With the decrease of soil moisture from 50 to $20 \%$, soluble protein, glutamic acid, and proline contents significantly increased by $19.58-88.99 \%$, 19.40-87.84\%, and 20.46-97.19\%, respectively. Compared with SM50, SM30 and SM20 treatments significantly increased GABA and soluble sugar contents. Lower P5C contents were recorded in SM40, SM30, and SM20 treatments than in SM50.

\section{Expression Levels of Genes Related to 2-AP Biosynthesis}

Figure 4 shows the transcript levels of $P R O D H, B A D H 2, D A O 1$, DAO2, DAO4, DAO5, OAT, P5CS1, and P5CS2 under different soil moisture. Compared with SM50, SM40, SM30, and SM20 treatments significantly $(p<0.05)$ decreased transcript levels of PRODH, DAO4, DAO5, and OAT by 21.45-44.94\%, 32.74-54.85\%, and $54.18-71.70 \%$, respectively. The transcript level of $B A D H 2$ decreased with the decline of soil moisture, but the differences among all treatments are not significant. 58.19, 45.05, and $548.05 \%$ higher transcript levels of DAO1 were recorded in SM40, SM30, and SM20 treatments than in SM50, respectively. 31.74 and $33.22 \%$ lower transcript levels of DAO2 were recorded in SM30 and SM20 treatments than in SM50, respectively. Compared with SM50, SM40, SM30, and SM20 treatments significantly decreased transcript levels of P5CS2. There was no significant difference among SM50, SM40, and SM30 treatments in transcript level of P5CS1, but 33.54\% lower transcript level was recorded in SM20 treatment than in SM50 treatment.

\section{PDH, P5CS, BADH, OAT, and DAO Activities}

Different soil moisture substantially regulated $\mathrm{PDH}, \mathrm{P} 5 \mathrm{CS}$, $\mathrm{BADH}, \mathrm{OAT}$, and DAO activities (Figure 5). Compared with SM50, SM40, SM30, and SM20 treatments significantly $(p<0.05)$

TABLE 2 | Effect of different soil moisture contents on growth parameters of fragrant rice plants.

\begin{tabular}{|c|c|c|c|c|c|}
\hline Treatment & Plant height (cm) & Stem width (mm) & Fresh weight (mg plant-1) & Dry weight (mg plant-1) & Relative water content (\%) \\
\hline SM50 & $20.05 \pm 1.03 a$ & $2.18 \pm 0.09 a$ & $188.89 \pm 14.35 a$ & $42.33 \pm 3.21 \mathrm{a}$ & $77.51 \pm 1.99 a$ \\
\hline SM40 & $20.89 \pm 1.22 a$ & $2.19 \pm 0.15 a$ & $172.22 \pm 13.84 b$ & $41.00 \pm 2.83 a$ & $76.06 \pm 2.46 a b$ \\
\hline SM30 & $20.07 \pm 1.11 a$ & $2.27 \pm 0.11 \mathrm{a}$ & $169.44 \pm 9.98 b$ & $40.89 \pm 3.48 a$ & $75.79 \pm 2.62 a b$ \\
\hline SM20 & $20.22 \pm 1.33 a$ & $2.24 \pm 0.12 a$ & $171.56 \pm 13.56 b$ & $42.11 \pm 2.85 a$ & $75.37 \pm 1.90 b$ \\
\hline
\end{tabular}

Data represent the mean of five data \pm standard error. Different letter above the table indicates difference at $p<0.05$ by $L S D$ tests. 


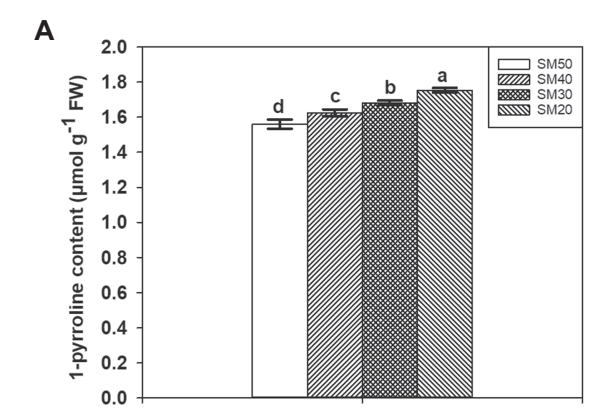

D

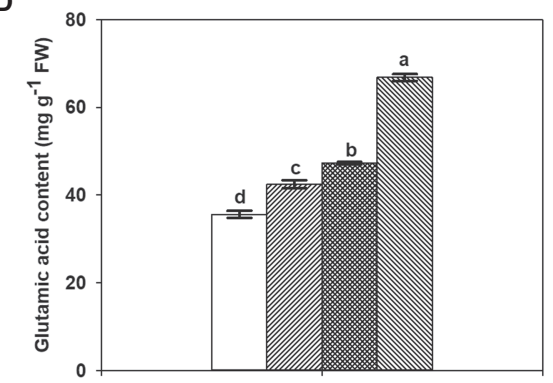

G

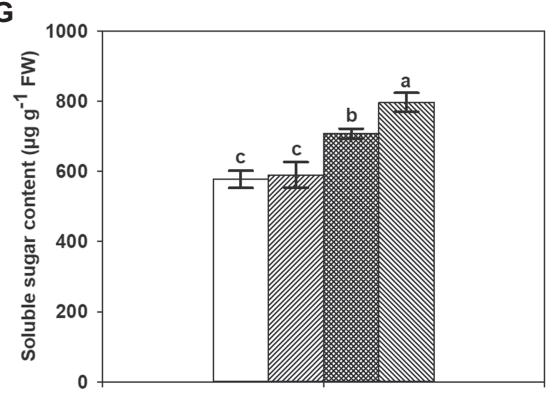

$B$

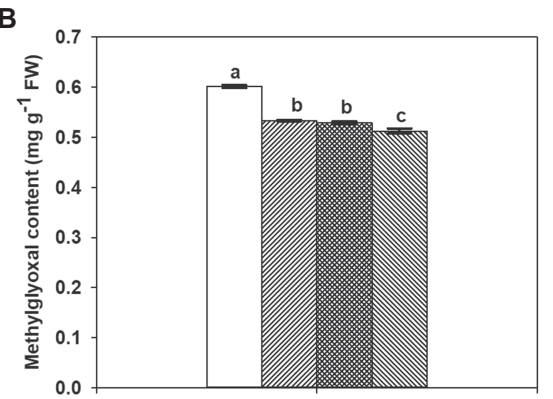

E

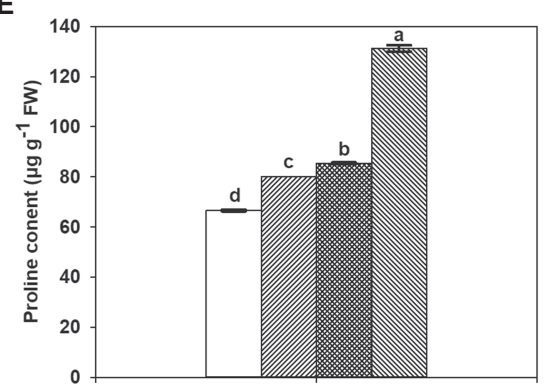

H

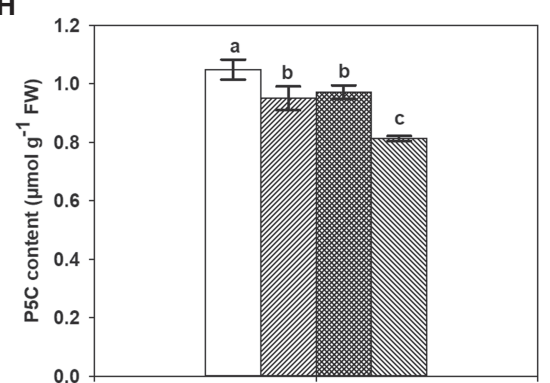

C

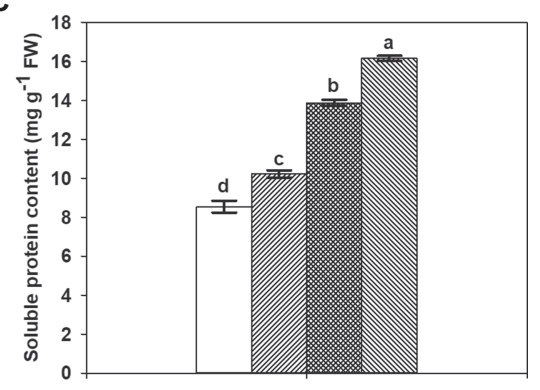

$\mathbf{F}$

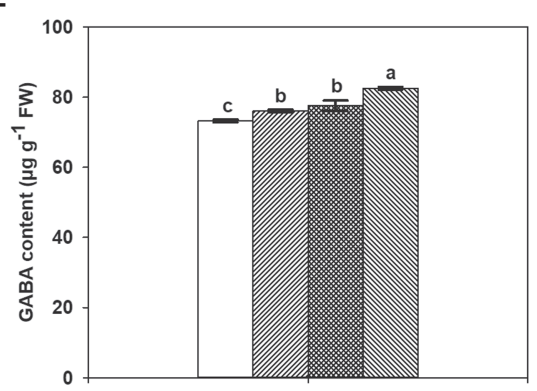

FIGURE 3 | Effects of different soil moisture contents on 1-pyrroline (A), methylglyoxal (B), soluble protein (C), glutamic acid (D), proline (E), GABA (F), soluble sugar $(\mathbf{G})$, and P5C $\mathbf{( H )}$ contents in fragrant rice. Each column represents the mean of three data \pm standard error $(n=3)$. Bars sharing a common letter do not differ significantly at $(p<0.05)$.

reduced $\mathrm{PDH}$ activity by $8.98,5.26$, and $22.83 \%$, respectively. There was no significant difference between SM50 treatment and SM40 treatment in P5CS activity but SM30 and SM20 treatments significantly reduced P5CS activity compared with SM50. Lower BADH and OAT activities were recorded in SM40, SM30, and SM20 treatments than in SM50. 35.56, 24.66, and $64.24 \%$ higher DAO activities were recorded in SM40, SM30, and SM20 treatments than in SM50, respectively.

\section{Correlation Analysis}

The heat map of the correlations among the enzymes activities, biochemical substances contents, genes expressions, and 2-AP content is presented in Figure 6. 2-AP content in fragrant rice was negatively correlated with soil moisture content. There were positive correlations among 2-AP content, the transcript level of DAO1, and DAO activity. Glutamic acid, proline, and GABA contents negatively correlated with soil moisture. The transcript levels of $P R O D H, B A D H 2, D A O 2$, DAO4, DAO5, OAT, P5CS1, and P5CS2 negatively correlated with 2-AP but positively correlated with soil moisture content, and similar trends were observed in activities of $\mathrm{PDH}, \mathrm{P} 5 \mathrm{CS}$, $\mathrm{BADH}$, and OAT.

\section{DISCUSSION}

The rice aroma with 2-AP as the key compound is a highly heritable trait governed by genes, although rice varieties with aromatic properties differ genetically (Okpala et al., 2019). The present study revealed the effects of different soil moisture contents on 2-AP biosynthesis in fragrant rice. Our results showed that the lower the soil moisture, the higher the 2-AP. Similar results were also reported by Deng et al. (2018), who demonstrated that a decline of soil water potential could remarkably increase 2-AP content. Our results also showed that the low soil moisture would not inhibit the growth of fragrant rice when it is not less than $20 \%$ for 10 days according to the determined growth parameters (plant height, stem width, and dry weight). These results were consistent with previous studies, which showed that intermittent drought would not affect rice growth or reduce grain yield (Wang et al., 2016; Zhang et al., 2021). Our results 


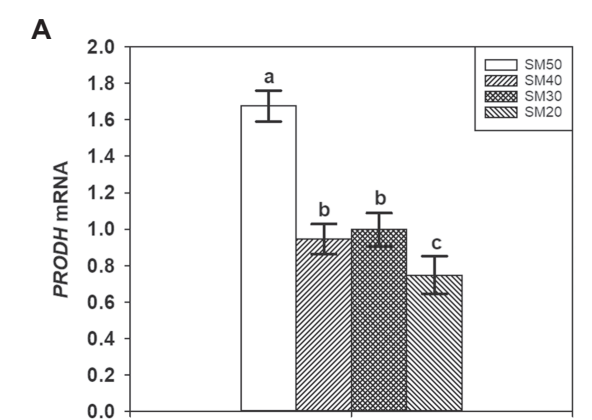

D

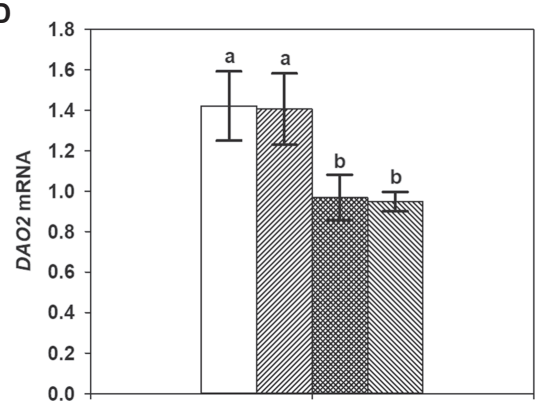

G

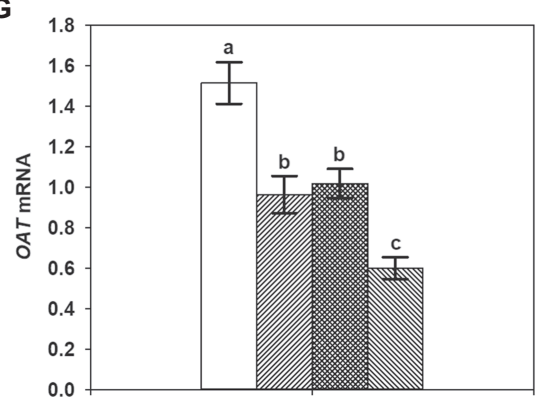

B

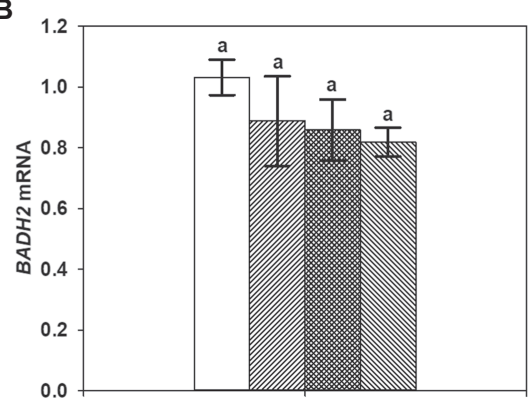

E

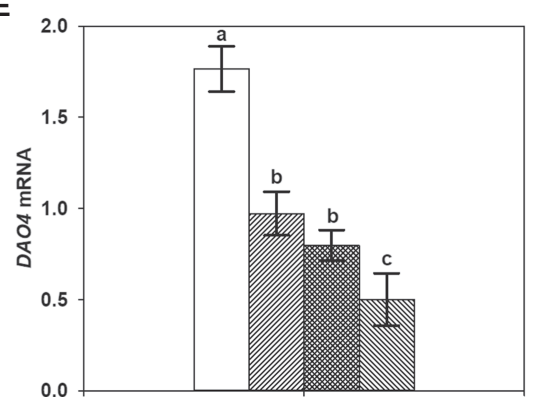

H

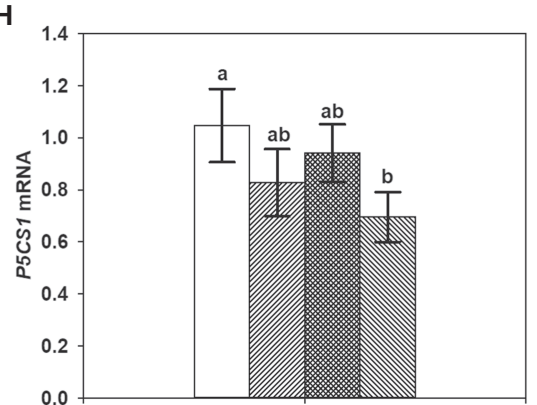

C

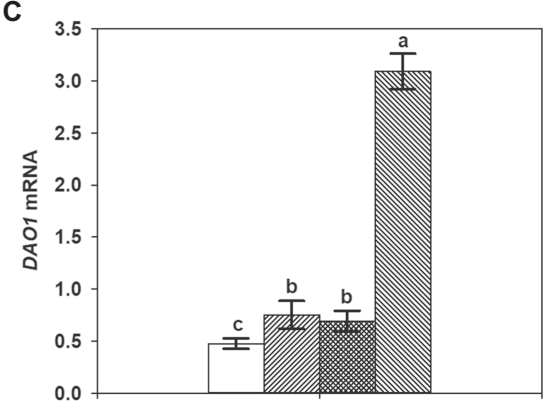

F

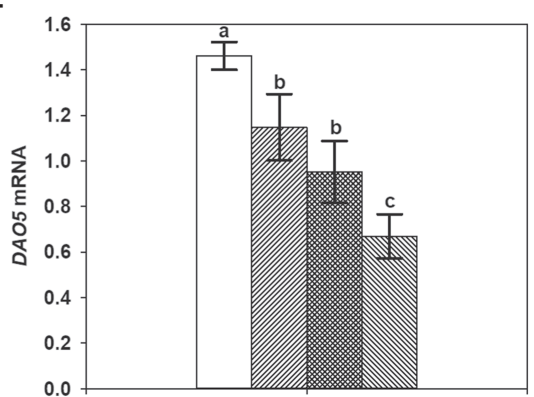

I

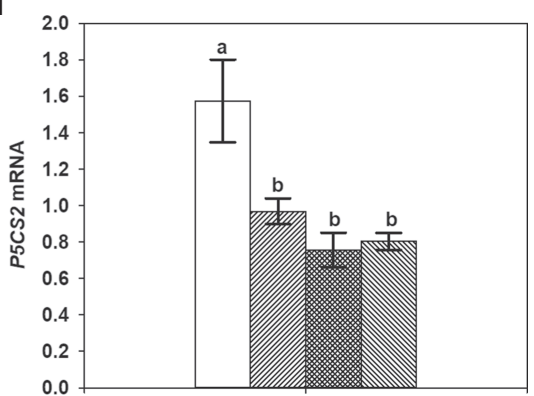

FIGURE 4 | Effects of different soil moisture contents on expression levels of PRODH (A), BADH2 (B), DAO1 (C), DAO2 (D), DAO4 (E), DAO5 (F), OAT (G), P5CS1 (H), and P5CS2 (I) in fragrant rice. Each column represents the mean of three data \pm standard error $(n=3)$. Bars sharing a common letter do not differ significantly at $(p<0.05)$.

were consistent with the study by Mo et al. (2019b), who indicated that suitable drought treatment could increase 2-AP content without inhibiting the productivity of fragrant rice.

Our study observed that high 2-AP induced by low soil moisture accompanied by proline accumulation. Our results agreed with the study by Mo et al. (2019a), who showed that decreased water potential increased both proline and 2-AP contents in fragrant rice and demonstrated that the increased 2-AP was attributed to the enhanced conversion from proline to 2-AP. However, this theory contrasts with the results of the present study. Although the proline content was increased in low soil moisture treatments (SM40, SM30, and SM20, compared with SM50), $\mathrm{PDH}$, which plays a crucial part in proline degradation (Huang et al., 2007; Luo et al., 2021), presented an opposite trend in its activity. The results of our study were consistent with the study by Amist and Singh (2017), which showed that PDH activity in wheat plants substantially declined under drought stress. The decline of ProDH activity could be attributed to the transcript reduction. In addition, P5CS and OAT, which are enzymes involved in proline metabolism and responsible for converting glutamic acid and ornithine to proline (Hien et al., 2003; Hinge et al., 2016), displayed lower activities under low soil moisture treatments. Real-time PCR analyses also showed that the expression of OAT, P5CS1, and P5CS2 decreased in low soil moisture treatments. Therefore, we deduced that the increase of proline is mainly due to $\mathrm{ProDH}$ inhibition. There is possible that P5CS and OAT were induced in earlier times of the soil moisture conditions, and part of the increased proline came from the protein degradation (Trovato et al., 2019). Either way, the decline of PDH activity induced by reducing $P R O D H$ expression indicated that the proline pathway is not the major way to biosynthesize 2-AP in fragrant rice under low soil moisture.

Moreover, glutamic acid is the precursor of both proline and 2-AP (Yoshihashi et al., 2002; Szabados and Savouré, 2010). In our study, the contents of glutamic acid significantly increased with the decline of soil moisture. This result was inconsistent with the study by Woodrow et al. (2017), who indicated that glutamic acid decreased when proline increased 
A

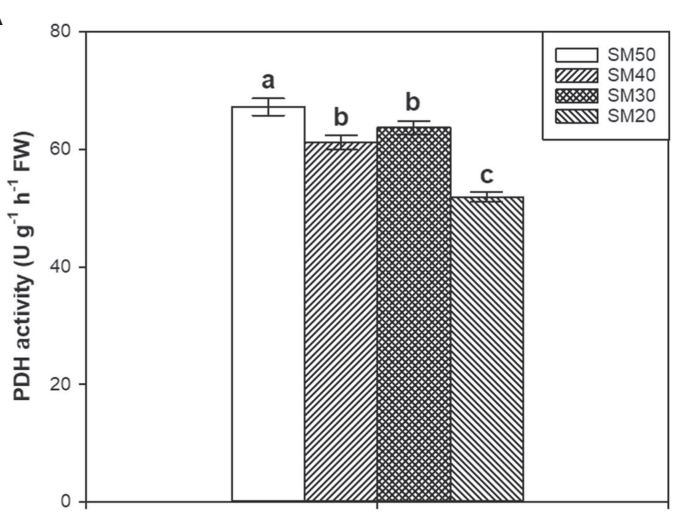

C

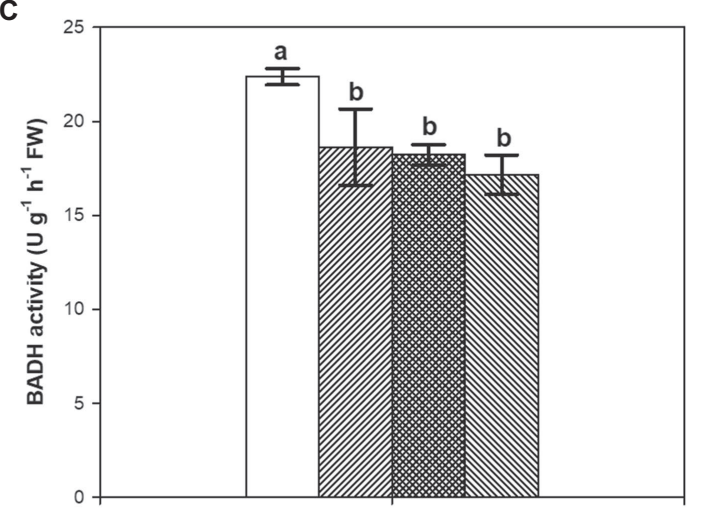

E

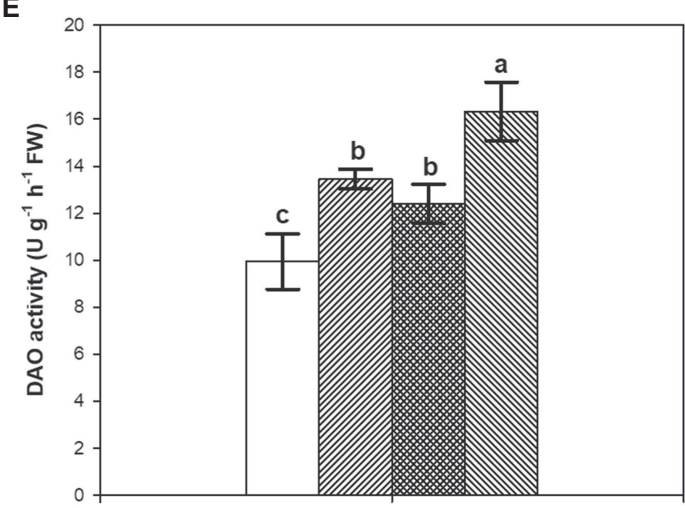

B

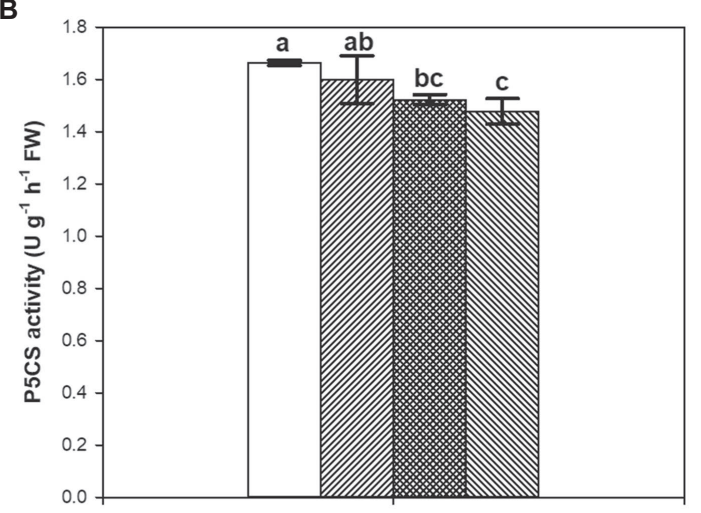

D

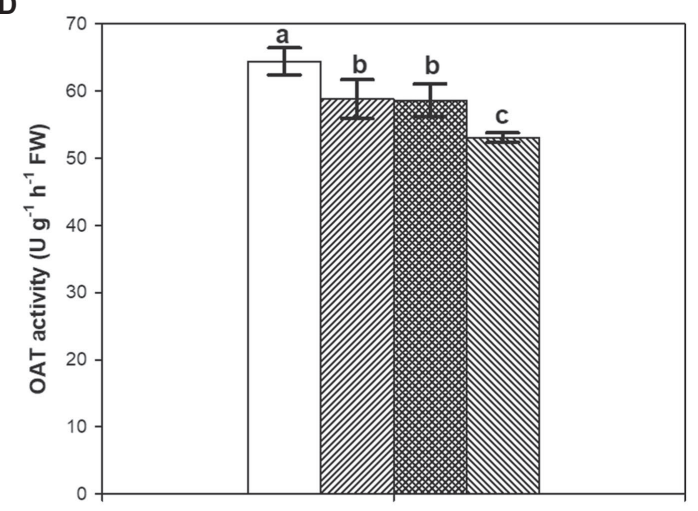

FIGURE 5 | Effects of different soil moisture contents on activities of PDH (A), P5CS (B), BADH (C), OAT (D), and DAO (E) in fragrant rice. Each column represents the mean of three data \pm standard error $(n=3)$. Bars sharing a common letter do not differ significantly at $(p<0.05)$.

under stress conditions. The present study showed that low soil moisture significantly increased glutamic acid by inhibiting its degradation. The P5CS and its encoded gene (P5CS1, P5CS2), which correspond to the degradation of glutamic acid, exhibited lower activity and transcript levels under low soil moisture. The differences between our results and previous reports could be explained by different plant species and the strength and duration of drought. The drought condition in the present study did not cause real stress because there was no substant inhibition in rice growth or reduction of RWC. We deduced that the proline accumulation induced the decline of P5CS activity and expression of genes, thus causing the accumulation of glutamic acid. More studies need to be conducted to investigate the effects of soil moisture on glutamate biosynthesis in rice.

The results of our study contrasted with the study by Bao et al. (2018), which showed that alternate wetting and drying treatment increased 2-AP content in fragrant rice by enhancing $\mathrm{PDH}$ activity and improving the expression of $P R O D H$. Although alternate wetting and drying irrigation would periodically decrease soil moisture, it has the part of recovery, and the compensation effect often occurs after the recovery. The previous study has found that recovery after the drought treatment would induce proline degradation, and it was attributed to 


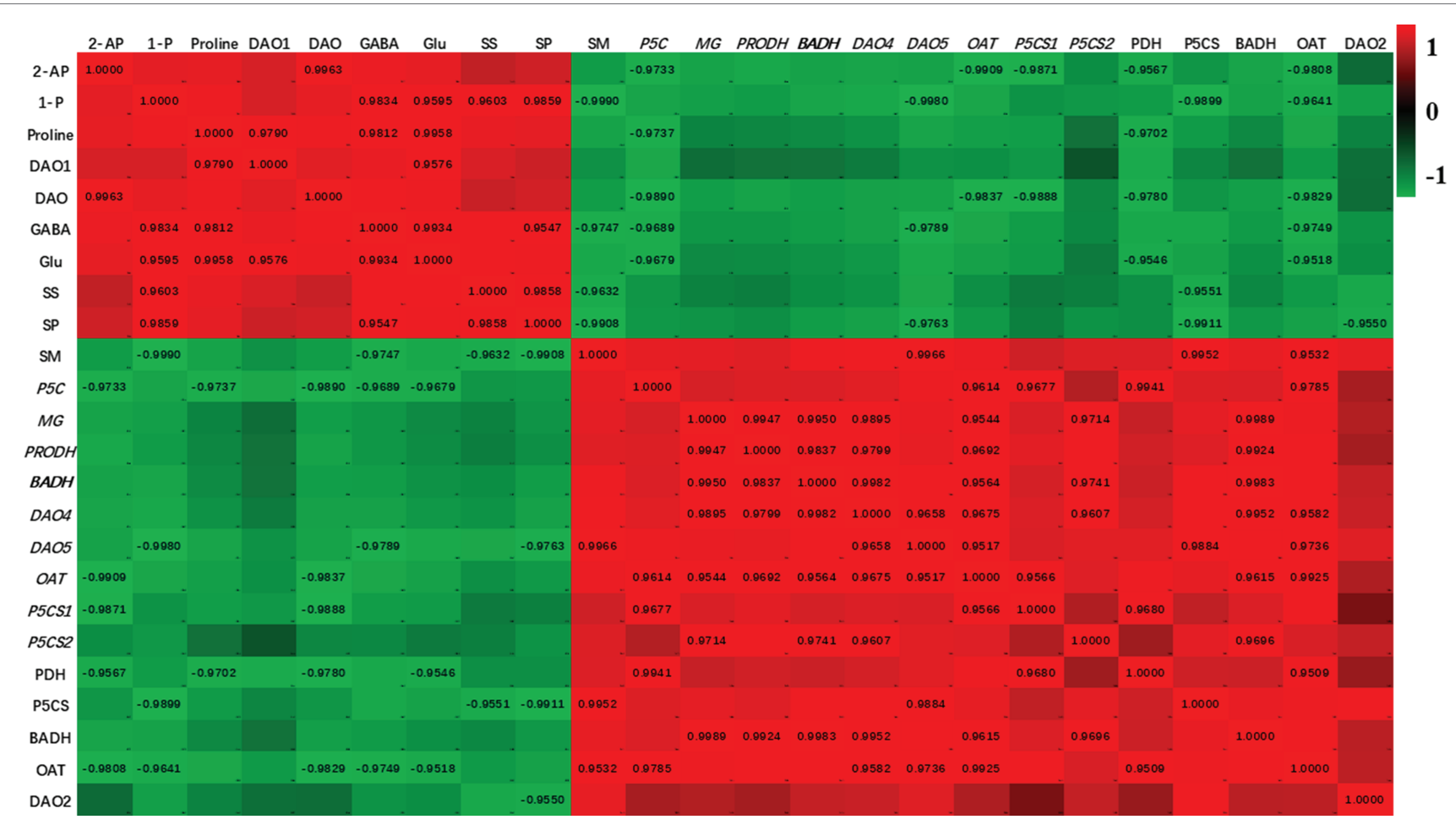

FIGURE 6 | The heatmap for the investigated parameters. Values are fit constants (only show when $p<0.05)$. 2-AP, 2-acetyl-1-pyrroline; SM, soil moisture content; 1-P, 1-pyrroline content; MG, methylglyoxal content; SP, soluble sugar content; Glu, glutamic acid content: SS, soluble sugar content; P5C, pyrroline-5-carboxylic acid; $\mathrm{PDH}$, proline dehydrogenase; P5CS, pyrroline-5-carboxylate synthetase; BADH, betaine aldehyde dehydrogenase; OAT, ornithine transaminase; DAO, diamine oxidase.

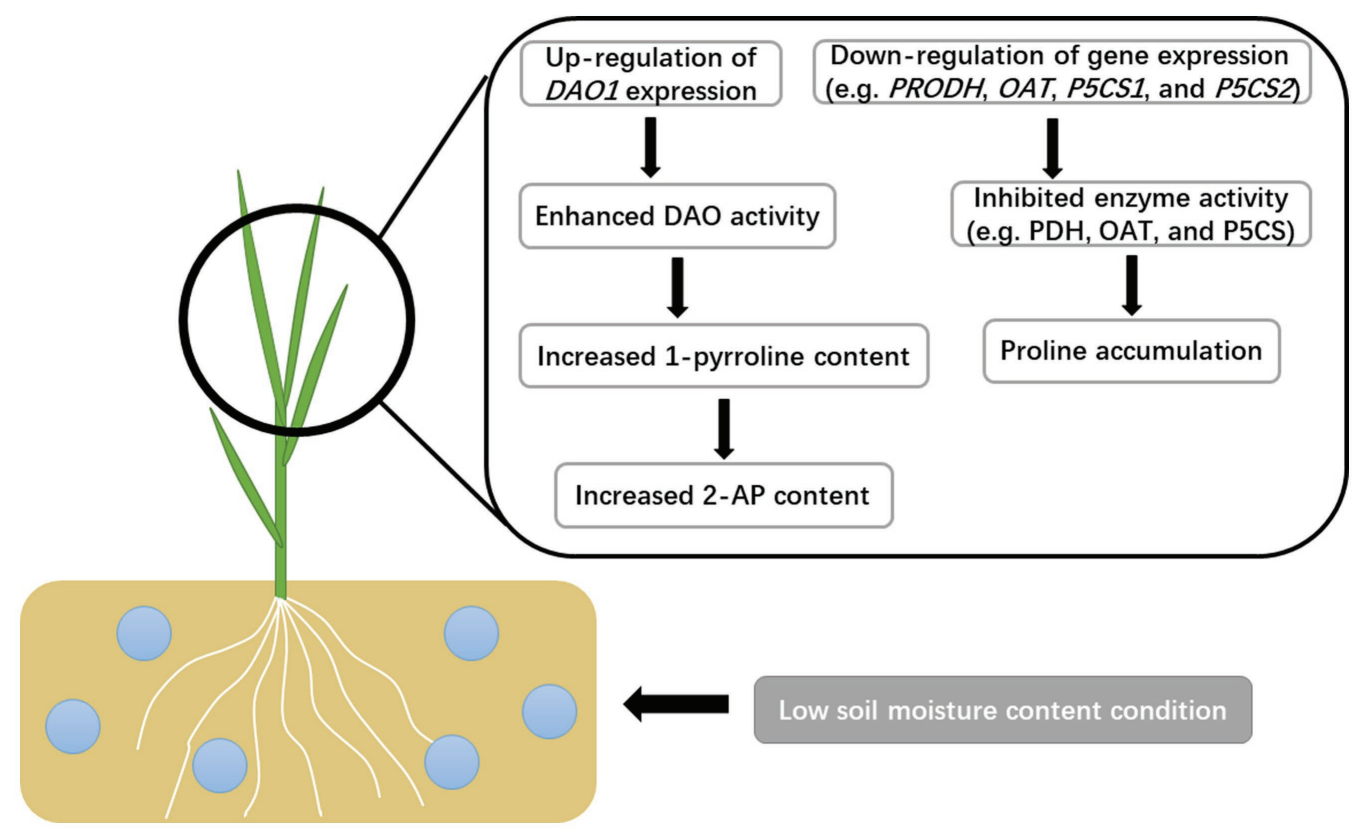

FIGURE 7 | The potential mechanism of soil moisture in regulating the 2-AP biosynthesis in fragrant rice.

the enhancement of PDH activity (Kiyosue et al., 1996; Foster et al., 2015). Thus, we deduced that the 2-AP biosynthesis in fragrant rice mainly depended on the proline pathway only during the recovery phase (wet period) in alternate wetting and drying irrigation. However, the 2-AP biosynthesis relies more on other pathways under drought conditions. 
Besides the proline pathway, ornithine would convert to putrescine, then to $\gamma$-aminobutyric aldehyde, and then to 1-pyrroline synthesizes 2-AP in fragrant rice (Wakte et al., 2017; Bao et al., 2018). DAO transformed putrescine into $\gamma$-aminobutyric aldehyde, which further cyclizes spontaneously to 1-pyrroline, the limiting precursor of 2-AP (Struve and Christophersen, 2003; Ghosh and Roychoudhury, 2017). Our study noted the enhanced DAO activity and increased 1-pyrroline content under low soil moisture treatments. The transcript level of DAO1 was greatly improved, especially in SM20 treatment, although the transcript levels of DAO2, DAO4, and DAO5 presented decreased trends with the decline of soil moisture. The correlation analysis showed that increased 2-AP positively correlated with both DAO1 expression and DAO activity. Hence, we deduced that increased 2-AP content under low soil moisture could be attributed to the DAO pathway and mainly regulated by the expression of DAO1.

In addition, rice growth could be divided into several stages, including seedling, tillering, booting, heading, grain-filling, and maturity. There is possible that the 2-AP synthesis pathway is changing with development and organ. Furthermore, during the heading to maturity stage, the dry weight and some biochemical substances would be transported from vegetative organs to reproductive organs, that is, grains (Liu et al., 2019). It is unknown that whether the 2-AP and its precursors would be transported inside fragrant rice. Thus, more studies need to be conducted to investigate the 2-AP biosynthesis and its response to soil moisture under different growing phases.

In conclusion, the present study indicated that enhanced 2-AP production in fragrant rice plants under low soil moisture was mainly through the upregulation of DAO1 expression to promote the conversion from putrescine to 2-AP (Figure 7), while the proline pathway was inhibited. In fragrant rice

\section{REFERENCES}

Amist, N., and Singh, N. B. (2017). Responses of enzymes involved in proline biosynthesis and degradation in wheat seedlings under stress. Allelopath. J. 42, 195-205. doi: 10.26651/allelo.j/2017-42-2-1116

Banu, M. N. A., Hoque, M. A., Watanabe-sugimoto, M., Islam, M. M., Uraji, M., Matsuoka, K., et al. (2010). Proline and glycinebetaine ameliorated $\mathrm{NaCl}$ stressvia scavenging of hydrogen peroxide and methylglyoxal but not superoxide or nitric oxide in tobacco cultured cells. Biosci. Biotechnol. Biochem. 74, 2043-2049. doi: 10.1271/bbb.100334

Bao, G., Ashraf, U., Wang, C., He, L., Wei, X., Zheng, A., et al. (2018). Molecular basis for increased 2-acetyl-1-pyrroline contents under alternate wetting and drying (AWD) conditions in fragrant rice. Plant Physiol. Biochem. 133, 149-157. doi: 10.1016/j.plaphy.2018.10.032

Bates, L. S., Waldren, R. P., and Teare, I. D. (1973). Rapid determination of free proline for water-stress studies. Plant Soil 39, 205-207. doi: 10.1007/BF00018060

Chen, S., Yang, Y., Shi, W., Ji, Q., He, F., Zhang, Z., et al. (2008). Badh2, encoding betaine aldehyde dehydrogenase, inhibits the biosynthesis of 2-Acetyl-1-Pyrroline, a major component in rice fragrance. Plant Cell 20, 1850-1861. doi: 10.1105/tpc.108.058917

Deng, Q. Q., Ashraf, U., Cheng, S. R., Sabir, S. R., Mo, Z. W., Pan, S. G., et al. (2018). Mild drought in interaction with additional nitrogen dose at grain filling stage modulates 2acetyl-1-pyrroline biosynthesis and grain yield in fragrant rice. Appl. Ecol. Environ. Res. 16, 7741-7758. doi: 10.15666/aeer/1606_77417758

Dumitrascu, C., Fiamegos, Y., and de la Calle Guntinas, M. B. (2021). Feasibility study on the use of elemental profiles to authenticate aromatic rice: the production, applying a moderate water deficit that does not significantly reduce the RWC, growth, and yield could be considered for the increment of aroma.

\section{DATA AVAILABILITY STATEMENT}

The original contributions presented in the study are included in the article/Supplementary Material, and further inquiries can be directed to the corresponding author.

\section{AUTHOR CONTRIBUTIONS}

XT initiated and designed the research. HL, MD, LK, LH, YC, and ZW performed the experiments. HL analyzed the data and wrote the manuscript. All authors contributed to the article and approved the submitted version.

\section{FUNDING}

This study was supported by National Natural Science Foundation of China (31971843), The Technology System of Modern Agricultural Industry in Guangdong (2020KJ105), and Guangzhou Science and Technology Project (202103000075).

\section{SUPPLEMENTARY MATERIAL}

The Supplementary Material for this article can be found online at: https://www.frontiersin.org/articles/10.3389/fpls.2021.772728/ full\#supplementary-material

case of basmati and thai rice. Anal. Bioanal. Chem. 413, 4947-4957. doi: 10.1007/s00216-021-03455-9

Farrell, C., Szota, C., and Arndt, S. K. (2017). Does the turgor loss point characterize drought response in dryland plants? Plant Cell Environ. 40, 1500-1511. doi: 10.1111/pce.12948

Foster, K., Lambers, H., Real, D., Ramankutty, P., Cawthray, G. R., and Ryan, M. H. (2015). Drought resistance and recovery in mature Bituminaria bituminosa var. albomarginata. Ann. Appl. Biol. 166, 154-169. doi: 10.1111/aab.12171

Ghosh, P., and Roychoudhury, A. (2017). Differential levels of metabolites and enzymes related to aroma formation in aromatic indica rice varieties: comparison with non-aromatic varieties. 3 Biotech 8:25. doi: 10.1007/ s13205-017-1045-6

Hien, D. T., Jacobs, M., Angenon, G., Hermans, C., Thu, T. T., Son, L. V., et al. (2003). Proline accumulation and $\Delta 1$-pyrroline-5-carboxylate synthetase gene properties in three rice cultivars differing in salinity and drought tolerance. Plant Sci. 165, 1059-1068. doi: 10.1016/S0168-9452(03)00301-7

Hill, J. M. (1967). The inactivation of pea-seedling diamine oxidase by peroxidase and 1,5-diaminopentane. Biochem. J. 104, 1048-1055. doi: 10.1042/bj1041048

Hinge, V., Patil, H., and Nadaf, A. (2016). Comparative characterization of aroma volatiles and related gene expression analysis at vegetative and mature stages in basmati and non-basmati rice (Oryza sativa 1.) cultivars. Appl. Biochem. Biotechnol. 178, 619-639. doi: 10.1007/s12010-015-1898-2

Huang, T., Huang, Y., Hung, H., Ho, C., and Wu, M. (2007). Delta(1)-Pyrroline-5carboxylic acid formed by proline dehydrogenase from the Bacillus subtilis ssp natto expressed in Escherichia coli as a precursor for 2-acetyl-1-pyrroline. J. Agric. Food Chem. 55, 5097-5102. doi: 10.1021/jf0700576 
Jezussek, M., Juliano, B. O., and Schieberle, P. (2002). Comparison of key aroma compounds in cooked brown rice varieties based on aroma extract dilution analyses. J. Agric. Food Chem. 50, 1101-1105. doi: 10.1021/jf0108720

Kaikavoosi, K., Kad, T. D., Zanan, R. L., and Nadaf, A. B. (2015). 2-Acetyl-1pyrroline augmentation in scented indica rice (Oryza sativa L.) varieties through $\Delta$ 1-pyrroline-5-carboxylate synthetase (P5CS) gene transformation. Appl. Biochem. Biotechnol. 177, 1466-1479. doi: 10.1007/s12010-015-1827-4

Kiyosue, T., Yoshiba, Y., Yamaguchi-Shinozaki, K., and Shinozaki, K. (1996). A nuclear gene encoding mitochondrial proline dehydrogenase, an enzyme involved in proline metabolism, is up-regulated by proline but downregulated by dehydration in Arabidopsis. Plant Cell 8, 1323-1335. doi: 10.1105/tpc.8.8.1323

Li, Y., Mo, Z., Li, Y., Nie, J., Kong, L., Ashraf, U., et al. (2021). Additional nitrogen application under different water regimes at tillering stage enhanced rice yield and 2-acetyl-1-pyrroline (2AP) content in fragrant rice. J. Plant Growth Regul. doi: 10.1007/s00344-021-10351-0

Liu, K., Yang, R., Lu, J., Wang, X., Lu, B., Tian, X., et al. (2019). Radiation use efficiency and source-sink changes of super hybrid rice under shade stress during grain-filling stage. Agron. J. 111, 1788-1798. doi: 10.2134/agronj2018.10.0662

Luo, H., Chen, Y., He, L., and Tang, X. (2021). Lanthanum (La) improves growth, yield formation and 2-acetyl-1-pyrroline biosynthesis in aromatic rice (Oryza sativa L.). BMC Plant Biol. 21:233. doi: 10.1186/s12870-021-03006-5

Mahattanatawee, K., and Rouseff, R. L. (2014). Comparison of aroma active and sulfur volatiles in three fragrant rice cultivars using GC-Olfactometry and GC-PFPD. Food Chem. 154, 1-6. doi: 10.1016/j.foodchem.2013.12.105

Mo, Z., Li, Y., Nie, J., He, L., Pan, S., Duan, M., et al. (2019a). Nitrogen application and different water regimes at booting stage improved yield and 2-acetyl-1-pyrroline (2AP) formation in fragrant rice. Rice 12:74. doi: 10.1186/ s12284-019-0328-4

Mo, Z., Tang, Y., Ashraf, U., Pan, S., Duan, M., Tian, H., et al. (2019b). Regulations in 2-acetyl-1-pyrroline contents in fragrant rice are associated with water-nitrogen dynamics and plant nutrient contents. J. Cereal Sci. 88, 96-102. doi: 10.1016/j.jcs.2019.05.013

Moogi, S., Lee, J., Jae, J., Sonne, C., Rinklebe, J., Heui Kim, D., et al. (2021). Valorization of rice husk to aromatics via thermocatalytic conversion in the presence of decomposed methane. Chem. Eng. J. 417:129264. doi: 10.1016/j. cej.2021.129264

Mostofa, M. G., Rahman, M. M., Siddiqui, M. N., Fujita, M., and Tran, L. P. (2020). Salicylic acid antagonizes selenium phytotoxicity in rice: selenium homeostasis, oxidative stress metabolism and methylglyoxal detoxification. J. Hazard. Mater. 394:122572. doi: 10.1016/j.jhazmat.2020.122572

Ncube, B., Finnie, J. F., and Van Staden, J. (2013). Dissecting the stress metabolic alterations in in vitro Cyrtanthus regenerants. Plant Physiol. Biochem. 65, 102-110. doi: 10.1016/j.plaphy.2013.01.001

Okpala, N. E., Mo, Z., Duan, M., and Tang, X. (2019). The genetics and biosynthesis of 2-acetyl-1-pyrroline in fragrant rice. Plant Physiol. Biochem. 135, 272-276. doi: 10.1016/j.plaphy.2018.12.012

Poonlaphdecha, J., Gantet, P., Maraval, I., Sauvage, F., Menut, C., Morère, A., et al. (2016). Biosynthesis of 2-acetyl-1-pyrroline in rice calli cultures: demonstration of 1-pyrroline as a limiting substrate. Food Chem. 197, 965-971. doi: 10.1016/j.foodchem.2015.11.060

Sánchez, E., Ruiz, J. M., and Romero, L. (2002). Proline metabolism in response to nitrogen toxicity in fruit of French bean plants (Phaseolus vulgaris L. cv strike). Sci. Hortic. 93, 225-233. doi: 10.1016/S0304-4238(01)00342-9

Struve, C., and Christophersen, C. (2003). Structural equilibrium and ring-chain tautomerism of aqueous solutions of 4-aminobutyraldehyde. Heterocycles 60, 1907-1914. doi: 10.3987/COM-03-9802
Szabados, L., and Savouré, A. (2010). Proline: a multifunctional amino acid. Trends Plant Sci. 15, 89-97. doi: 10.1016/j.tplants.2009.11.009

Thai, H. D., Takaragawa, H., Watanabe, K., Nakabaru, M., and Kawamitsu, Y. (2019). Leaf photosynthesis response to change of soil moisture content in sugarcane. Sugar Tech 21, 949-958. doi: 10.1007/s12355-019-00735-8

Trovato, M., Forlani, G., Signorelli, S., and Funck, D. (2019) Proline Metabolism and its Functions in Development and Stress Tolerance. Springer, Cham. 41-72.

Wakte, K., Zanan, R., Hinge, V., Khandagale, K., Nadaf, A., and Henry, R. (2017). Thirty-three years of 2-acetyl-1-pyrroline, a principal basmati aroma compound in scented rice (Oryza sativa L.): a status review. J. Sci. Food Agric. 97, 384-395. doi: 10.1002/jsfa.7875

Wang, A., Wang, L., Yi, H., and Zhao, Z. (2005). Research of determinat ion of glutamic acid by colorimetry (in Chinese). China Condiment, 50-52.

Wang, Z., Zhang, W., Beebout, S. S., Zhang, H., Liu, L., Yang, J., et al. (2016). Grain yield, water and nitrogen use efficiencies of rice as influenced by irrigation regimes and their interaction with nitrogen rates. Field Crop Res. 193, 54-69. doi: 10.1016/j.fcr.2016.03.006

Woodrow, P., Ciarmiello, L., Annunziata, M., Pacifico, S., Iannuzzi, F., Mirto, F., et al. (2017). Durum wheat seedling responses to simultaneous high light and salinity involve a fine reconfiguration of amino acids and carbohydrate metabolism. Physiol. Plant. 159, 290-312. doi: 10.1111/ppl.12513

Yan, L., Liu, C., Liang, H., Mao, X., Wang, F., Pang, C.-H., et al. (2012). Physiological responses to salt stress of T2 alfalfa progenies carrying a transgene for betaine aldehyde dehydrogenase. Plant Cell Tissue Org. Cult. 108, 191-199. doi: 10.1007/s11240-011-0027-3

Yang, R., Chen, H., and Gu, Z. (2011). Factors influencing diamine oxidase activity and $\gamma$-aminobutyric acid content of fava bean (Vicia faba L.) during germination. J. Agric. Food Chem. 59, 11616-11620. doi: 10.1021/ jf202645p

Yoshihashi, T., Huong, N. T. T., and Inatomi, H. (2002). Precursors of 2-acetyl-1pyrroline, a potent flavor compound of an aromatic rice variety. J. Agric. Food Chem. 50, 2001-2004. doi: 10.1021/jf011268s

Zhang, W., Yu, J., Xu, Y., Wang, Z., Liu, L., Zhang, H., et al. (2021). Alternate wetting and drying irrigation combined with the proportion of polymercoated urea and conventional urea rates increases grain yield, water and nitrogen use efficiencies in rice. Field Crop Res. 268:108165. doi: 10.1016/j. fcr.2021.108165

Conflict of Interest: The authors declare that the research was conducted in the absence of any commercial or financial relationships that could be construed as a potential conflict of interest.

Publisher's Note: All claims expressed in this article are solely those of the authors and do not necessarily represent those of their affiliated organizations, or those of the publisher, the editors and the reviewers. Any product that may be evaluated in this article, or claim that may be made by its manufacturer, is not guaranteed or endorsed by the publisher.

Copyright (c) 2021 Luo, Duan, Kong, He, Chen, Wang and Tang. This is an openaccess article distributed under the terms of the Creative Commons Attribution License (CC BY). The use, distribution or reproduction in other forums is permitted, provided the original author(s) and the copyright owner(s) are credited and that the original publication in this journal is cited, in accordance with accepted academic practice. No use, distribution or reproduction is permitted which does not comply with these terms. 